Supplement of Geosci. Model Dev., 11, 4987-5001, 2018

https://doi.org/10.5194/gmd-11-4987-2018-supplement

(C) Author(s) 2018. This work is distributed under

the Creative Commons Attribution 4.0 License.

(c) (1)

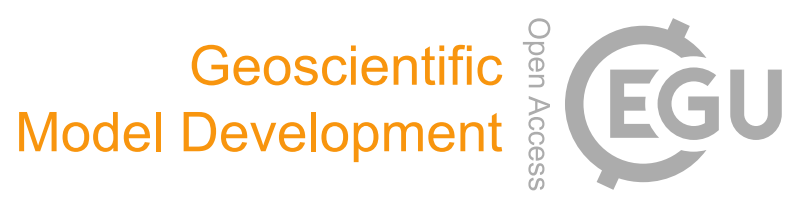

Supplement of

\title{
Two new submodels for the Modular Earth Submodel System (MESSy): New Aerosol Nucleation (NAN) and small ions (IONS) version 1.0
}

Sebastian Ehrhart et al.

Correspondence to: Sebastian Ehrhart (s.ehrhart@mpic.de)

The copyright of individual parts of the supplement might differ from the CC BY 4.0 License. 


\section{Contents}

1 IONS 2

1.1 IONS namelist . . . . . . . . . . . . . . . . . . . 2

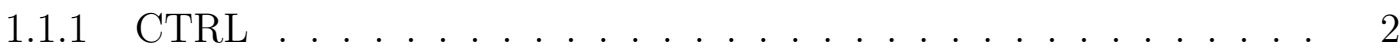

$1.1 .2 \mathrm{CPL} \ldots \ldots \ldots \ldots \ldots \ldots$

1.2 Additions in import.nml . . . . . . . . . . . . . . . 3

1.3 IONS channel objects . . . . . . . . . . . . . . . . . 3

2 NAN 5

2.1 NAN namelist . . . . . . . . . . . . . . . . . . 5

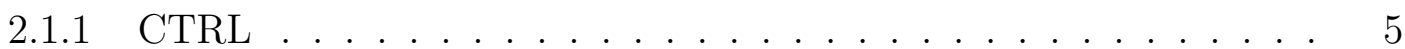

2.1 .2 NUC . . . . . . . . . . . . . . . . 6

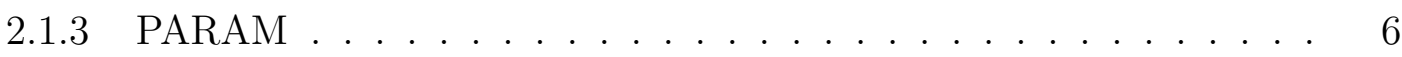

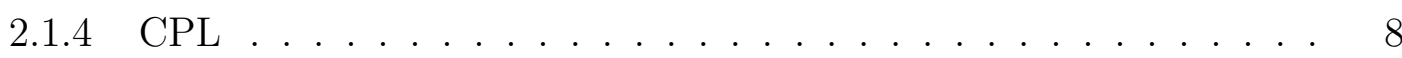

2.2 Channel Objects . . . . . . . . . . . . . . . . . . . . . . 10 


\section{IONS}

\subsection{IONS namelist}

The namelist file of the submodel IONS consists of the Fortran namelists CTRL and CPL. The content off each namelist is given in the beginning of each subsection. The combined namelist file is obtained by concatenating the individual namelists.

\subsubsection{CTRL}

Variables set in the namelist CTRL control the overall behaviour of the submodel.

\&CTRL

gcr_method $=2$

lqradon $=$. TRUE.

laero=.true.

/

- the integer variable gcr_method defines the method used for ion pair production rate due to GCR currently possible values are 0 for no GCR ionisation and 2 for GCR ionisation according to [Usoskin et al., 2010].

- Radon decay is included in the calculation of ion production, if Iqradon is set to TRUE.

- laero determines if ion aerosol coupling should be included in the calculation of steady state ion concentrations.

\subsubsection{CPL}

The CPL namelist sets variables needed for coupling to other submodels.

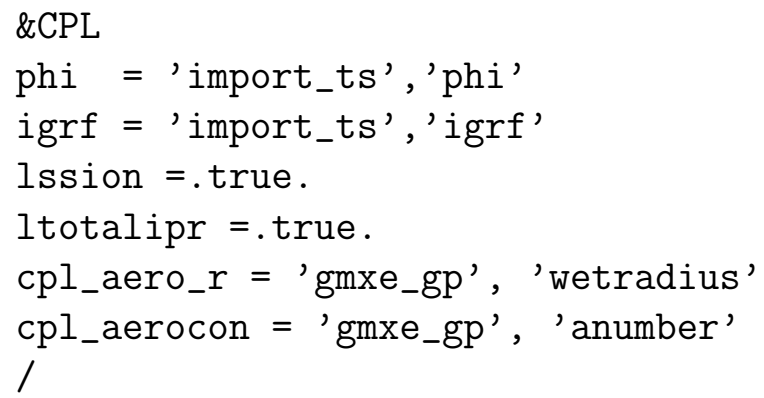

igrf and phi define which submodel provides the time series for the geomagnetic field and the GCR modulation. These variables are of MESSY's t_chaobj_cpl derived data type and contain the string variable cha, which defines the name of the submodel that imports the time series, and the variable obj, the name of the channel object. In the example namelist file the importing channel is import_ts. 
Ion aerosol interaction is defined by coupling IONS to variables from the aerosol models. The ion aerosol attachment coefficient can be calculated from aerosol particle concentration and radius. Alternatively, the condensation sink of a vapour, e.g. sulphuric acid, can be used as the ion-aerosol attachment coefficient by defining the coupling type.

- If the aerosol submodel provides a condensation sink, number of lost ions $\mathrm{s}^{-1}$, as a channel object it can be retrieved with cpl_aero_cs

- the radius of the the aerosol particles, in $\mathrm{m}$, can be used by coupling to the radius via cpl_aero_r

- and cpl_aerocon for the aerosol particle number concentration in $\mathrm{cm}^{-3}$.

\subsection{Additions in import.nml}

The variable name and path to time series and look up tables have to be included in the namelist file of the import submodel. For the time series this is in the namelist CTRL_TS:

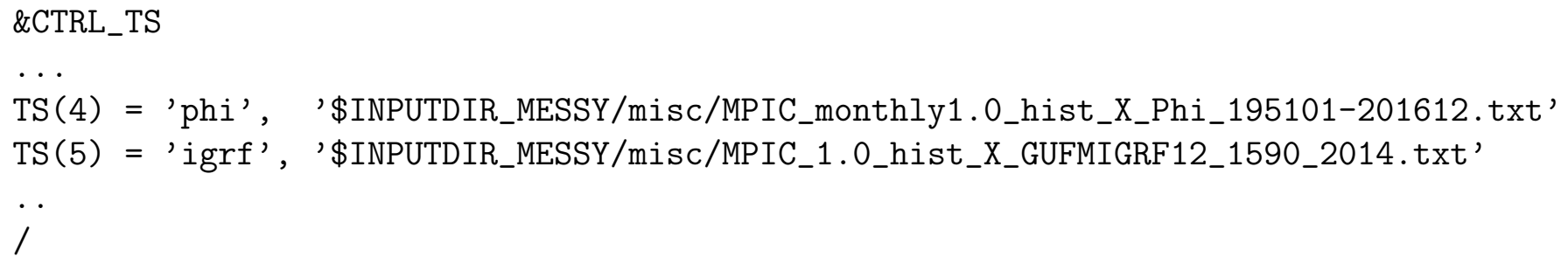

The look up table for the GCR induced ionisation has to be included in the namelist CTRL_LT:

$\mathrm{LT}(1)=$ 'CRII', '\$INPUTDIR_MESSY/LT_MPIC_1.0_CRII.nc' , 'CRII'

\subsection{IONS channel objects}

The IONS submodel provides output to other submodels as channel objects. Tracers or tracer tendencies are not changed in this submodel. The following objects are all defined as GP_3D_MID objects.

- total_ipr is the total ion pair production rate, the sum of ion pair production by GCR and Radon decay. Values are in $\mathrm{cm}^{-3} \mathrm{~s}^{-1}$.

- small_ions_neg and small_ions_pos are the concentration of small positive and negative ions assuming a steady state. Values are given in $\mathrm{cm}^{-3}$.

- $\mathrm{krec}$ is the recombination rate constant in $\mathrm{cm}^{6} \mathrm{~s}^{-1}$.

- radon_ipr is the ion pair production rate from Radon decay in $\mathrm{cm}^{-3} \mathrm{~s}^{-1}$. This channel object is only created by IONS if Iqradon is . TRUE. and $\mathrm{cpl} \mathbf{z}_{-} \mathrm{ipr} \_\mathrm{Rn} \% \mathrm{cha}$ was not set in the CPL namelist. 
- gcr_ipr is the ion pair production rate from galactic cosmic rays in $\mathrm{cm}^{-3} \mathrm{~s}^{-1}$. This channel object is only created by IONS if 1 gcr is . TRUE. and $c p l_{-} i p r \_g c r \% c h a$ was not set in the CPL namelist.

- aero_cs is created by IONS if laero is set to . TRUE. and cpl_aero_cs\%cha is set to an empty string or not initialised. aero_cs is the loss rate of ions onto aerosol particles in $\mathrm{cm}^{-3} \mathrm{~s}^{-1}$. 


\section{NAN}

\subsection{NAN namelist}

\subsubsection{CTRL}

\&CTRL

1 selnuc $(1)=$.FALSE.

Iselnuc (2) $=$.FALSE.

1 selnuc $(3)=$.FALSE.

lselnuc (4) $=$.TRUE.

lselnuc (5) $=$. TRUE.

lselnuc $(6)=$.TRUE.

1 selnuc $(7)=$.TRUE.

lselnuc $(8)=$.TRUE.

lselnuc $(9)=$. TRUE.

1 selnuc $(10)=$. TRUE.

nnucspec $=4$

nuclmethod='multi'

/

The set of nucleation parameterisation can be chosen via lselnuc. This variable is a vector of logical values, the index indicates the nucleation parameterisation, see table 1. Iselnuc (3) is not included in table 1 as it was originally used for the parameterisation given in [Merikanto et al., 2007]. However, this parameterisation required mixing ratios instead of vapour concentration. Due to more recent parameterisations from other sources the parameterisation is not fully implemented. Additionally the number of nucleating vapour species must be defined by nnucspec. A string variable indicating the algorithm used must be provided by nuclmethod. For multi-component nucleation this should be set to 'multi'. If GMXe is used the [Vehkamäki et al., 2002] parameterisation can be used by setting nuclmethod to 'vehk_gmxe'. 
Table 1: Summary of 1selnuc variables in the CTRL namelist, default value for all is .FALSE. .

\begin{tabular}{|l|l|l|}
\hline Variable & Parameterisation & involved species \\
\hline lselnuc (1) & [Vehkamäki et al., 2002] & $\mathrm{H}_{2} \mathrm{SO}_{4}$ \\
lselnuc (2) & [Kulmala et al., 1998] & $\mathrm{H}_{2} \mathrm{SO}_{4}$ \\
lselnuc (4) & [Dunne et al., 2016] & $\mathrm{H}_{2} \mathrm{SO}_{4}$ \\
lselnuc (5) & [Dunne et al., 2016] & $\mathrm{H}_{2} \mathrm{SO}_{4}, \mathrm{n}^{-}$ \\
lselnuc (6) & [Dunne et al., 2016] & $\mathrm{H}_{2} \mathrm{SO}_{4}, \mathrm{NH}_{3}$ \\
lselnuc(7) & [Dunne et al., 2016] & $\mathrm{H}_{2} \mathrm{SO}_{4}, \mathrm{NH}_{3}, \mathrm{n}^{-}$ \\
lselnuc(8) & [Riccobono et al., 2014] & $\mathrm{H}_{2} \mathrm{SO}_{4}$, Organic \\
lselnuc(9) & [Kirkby et al., 2016] & $\mathrm{H}_{2} \mathrm{SO}_{4}$, Organic \\
lselnuc(10) & [Kirkby et al., 2016] & $\mathrm{H}_{2} \mathrm{SO}_{4}$, Organic, $\mathrm{n}^{-}, \mathrm{n}^{+}$ \\
lselnuc(11) & [Almeida et al., 2013] & $\mathrm{H}_{2} \mathrm{SO}_{4}$, Amines \\
\hline
\end{tabular}

\subsubsection{NUC}

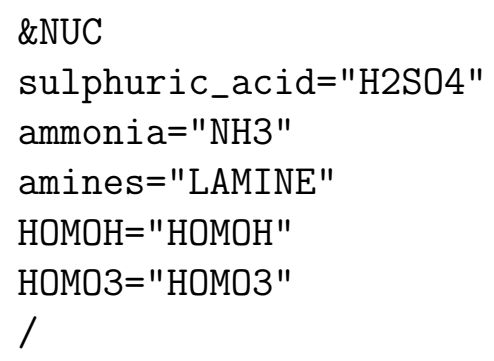

The only variables to set in the namelist NUC are the names of the nucleating vapours. This is important if the name of the species differs from the default name assumed in NAN. The variable names and default names are given above.

\subsubsection{PARAM}

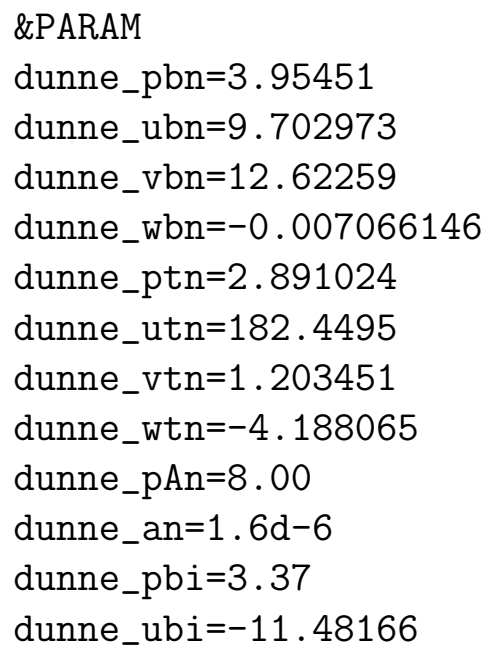




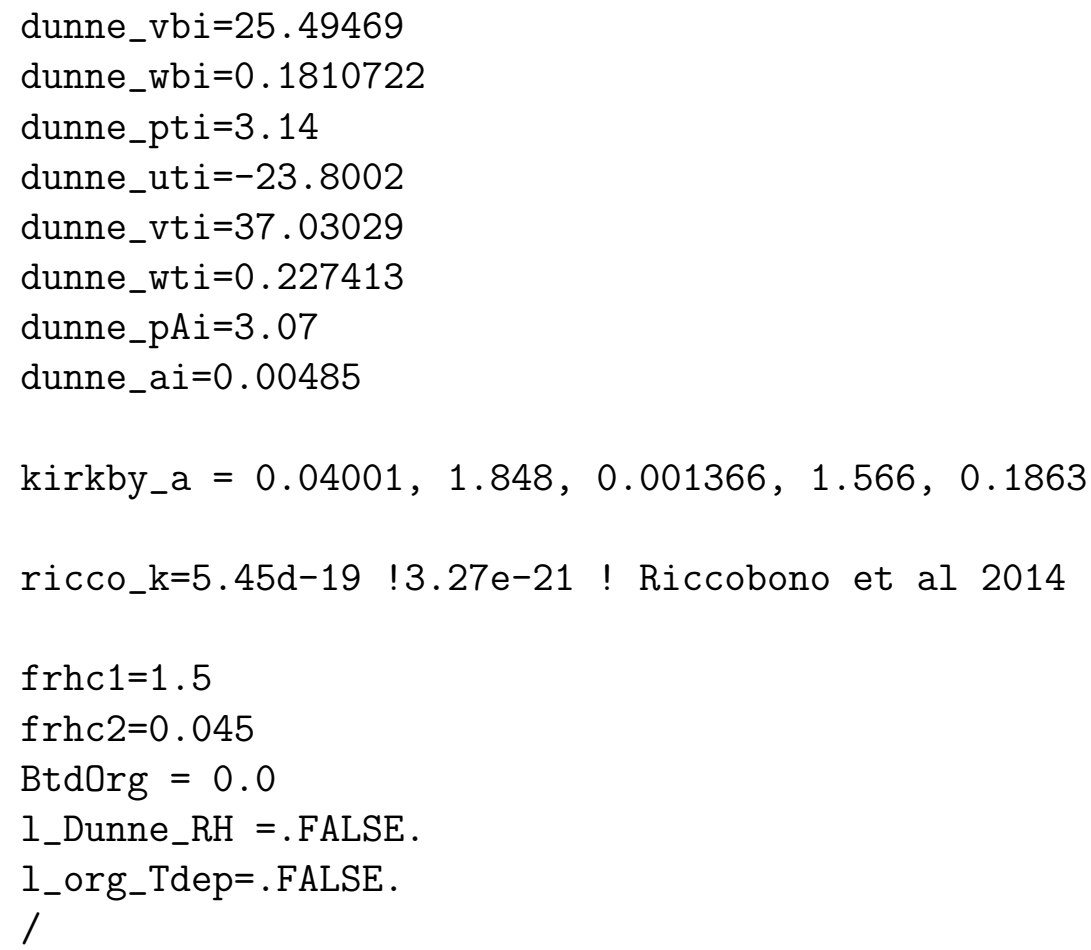

The namelist PARAM gives a large set of tuning parameters for the parameterisations. All parameters can be changed here without recompiling the model. A full list of parameters is given in table 2 together with the parameter symbol used in the main manuscript and the default value. The logical variables 1_org_Tdep and 1_Dunne_RH are not included in the tables since they provide simple switches for RH dependency of inorganic nucleation and temperature dependency for organic nucleation. 
Table 2: Summary of variables in the namelist PARAM, default value and symbol used in the main manuscript is also given.

\begin{tabular}{|l|l|l|}
\hline variable & default value & symbol \\
\hline dunne_pbn & 3.95451 & $p_{b, n}$ \\
dunne_ubn & 9.702973 & $u_{b, n}$ \\
dunne_vbn & 12.62259 & $v_{b, n}$ \\
dunne_wbn & -0.007066146 & $w_{b, n}$ \\
dunne_ptn & 2.891024 & $p_{t, n}$ \\
dunne_utn & 182.4495 & $u_{t, n}$ \\
dunne_vtn & 1.203451 & $v_{t, n}$ \\
dunne_wtn & -4.188065 & $w_{t, n}$ \\
dunne_pAn & 8.00 & $p_{a, n}$ \\
dunne_an & $1.6 \mathrm{~d}-6$ & $a_{n}$ \\
dunne_pbi & 3.37 & $p_{b, i}$ \\
dunne_ubi & -11.48166 & $u_{b, i}$ \\
dunne_vbi & 25.49469 & $v_{b, i}$ \\
dunne_wbi & 0.1810722 & $w_{b, i}$ \\
dunne_pti & 3.14 & $p_{t, i}$ \\
dunne_uti & -23.8002 & $u_{t, i}$ \\
dunne_vti & 37.03029 & $v_{t, i}$ \\
dunne_wti & 0.227413 & $w_{t, i}$ \\
dunne_pAi & 3.07 & $p_{a, i}$ \\
dunne_ai & 0.00485 & $a_{i}$ \\
kirkby_a(1) & 0.04001 & $a_{1}$ \\
kirkby_a(2) & 1.848 & $a_{2}$ \\
kirkby_a(3) & 0.001366 & $a_{3}$ \\
kirkby_a(4) & 1.566 & $a_{4}$ \\
kirkby_a(5) & 0.1863 & $a_{5}$ \\
ricco_k & $5.45 \mathrm{~d}-19$ & $k_{R i c}$ \\
frhc1 & 1.5 & $c_{1}$ \\
frhc2 & 0.045 & $c_{2}$ \\
BtdOrg & 0.0 & $B$ \\
\hline
\end{tabular}

\subsubsection{CPL}

\&CPL

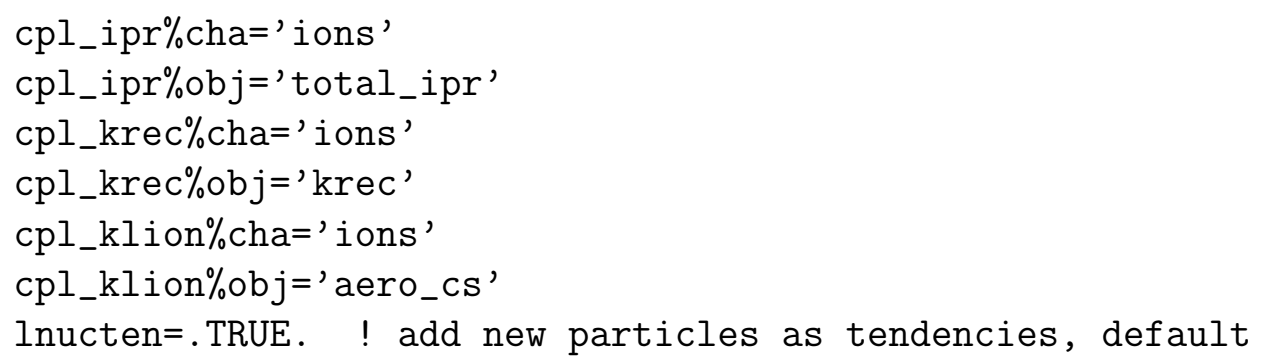


CPL controls the coupling of NAN to other submodels. The new parameterisations rely heavily on ion aerosol interaction, therefore several variables of the t_chaobj_cpl type are used here for coupling to the IONS submodel.

- $c p l_{-}$ipr defines the channel and channel object for the ion pair production rate in $\mathrm{cm}^{-3} \mathrm{~s}^{-1}$.

- $\mathrm{cpl}_{-} \mathrm{kli}$ ion is the ion-ion recombination in $\mathrm{cm}^{6} \mathrm{~s}^{-1}$.

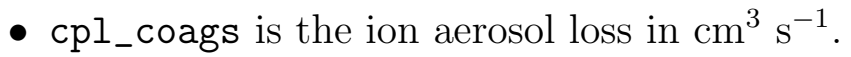

- aerosolmodel is a string variable and allows to set the channel name of the aerosol submodel, default is "GMXE".

Additionally to coupling to other submodels this namelist allows to control where in the Base Model Layer NAN is called.

- driver_call a string variable that can take the values "radiation" or "physc". Depending in whether the nucleation should be called in the radiation or general physics part of the base model. The default value is "physc"

- b4gmxe a logical value of TRUE indicates that NAN is called before GMXe. If set to FALSE NAN will be called after GMXe. This option makes only sense if driver_call is used to ensure that GMXe and NAN are called in the same basemodel subroutine.

Interaction between NAN and other aerosol models is further refined by the following variables

- Inucten a logical variable that defaults to .TRUE.. A true value results in NAN calculating nucleation mode particle tendencies, otherwise the tendency is not updated by NAN.

- Inucmode a logical variable, if . TRUE. NAN calculates the formation rate of particles in the nucleation mode, else the produced particles are grown to a size given by cpl_d2

- $c p 1$ d2 is a t_chaobj_cpl type variable that is set to the aerosol models lower mode diameters. 


\subsection{Channel Objects}

The NAN submodel provides several channel objects that can be used by other submodels.

- The number of freshly produced particles per unit volume is panew as number of particles $\mathrm{cm}^{-3}$.

- nucrate is the total formation rate of new particles in particles $\mathrm{cm}^{-3} \mathrm{~s}^{-1}$. Individual formation rates for each nucleation channel are also provided. Their channel object name is the same as the nucleation channel name within NAN.

- The use of panew or nucrate provides an alternative to updating the aerosol particle tracer tendency. If the Inucten is set to .FALSE. and the coupled aerosol model uses panew or nucrate to calculate the particle concentration.

\section{References}

[Almeida et al., 2013] Almeida, J., Schobesberger, S., Kürten, A., Ortega, I. K., Kupiainen-Maatta, O., Praplan, A. P., Adamov, A., Amorim, A., Bianchi, F., Breitenlechner, M., David, A., Dommen, J., Donahue, N. M., Downard, A., Dunne, E., Duplissy, J., Ehrhart, S., Flagan, R. C., Franchin, A., Guida, R., Hakala, J., Hansel, A., Heinritzi, M., Henschel, H., Jokinen, T., Junninen, H., Kajos, M., Kangasluoma, J., Keskinen, H., Kupc, A., Kurten, T., Kvashin, A. N., Laaksonen, A., Lehtipalo, K., Leiminger, M., Leppä, J., Loukonen, V., Makhmutov, V., Mathot, S., McGrath, M. J., Nieminen, T., Olenius, T., Onnela, A., Petäjä, T., Riccobono, F., Riipinen, I., Rissanen, M., Rondo, L., Ruuskanen, T., Santos, F. D., Sarnela, N., Schallhart, S., Schnitzhofer, R., Seinfeld, J. H., Simon, M., Sipila, M., Stozhkov, Y., Stratmann, F., Tome, A., Trostl, J., Tsagkogeorgas, G., Vaattovaara, P., Viisanen, Y., Virtanen, A., Vrtala, A., Wagner, P. E., Weingartner, E., Wex, H., Williamson, C., Wimmer, D., Ye, P., Yli-Juuti, T., Carslaw, K. S., Kulmala, M., Curtius, J., Baltensperger, U., Worsnop, D. R., Vehkamäki, H., and Kirkby, J. (2013). Molecular understanding of sulphuric acid-amine particle nucleation in the atmosphere. Nature, 502(7471):359363.

[Dunne et al., 2016] Dunne, E. M., Gordon, H., Kürten, A., Almeida, J., Duplissy, J., Williamson, C., Ortega, I. K., Pringle, K. J., Adamov, A., Baltensperger, U., Barmet, P., Benduhn, F., Bianchi, F., Breitenlechner, M., Clarke, A., Curtius, J., Dommen, J., Donahue, N. M., Ehrhart, S., Flagan, R. C., Franchin, A., Guida, R., Hakala, J., Hansel, A., Heinritzi, M., Jokinen, T., Kangasluoma, J., Kirkby, J., Kulmala, M., Kupc, A., Lawler, M. J., Lehtipalo, K., Makhmutov, V., Mann, G., Mathot, S., Merikanto, J., Miettinen, P., Nenes, A., Onnela, A., Rap, A., Reddington, C. L. S., Riccobono, F., Richards, N. A. D., Rissanen, M. P., Rondo, L., Sarnela, N., Schobesberger, S., Sengupta, K., Simon, M., Sipilä, M., Smith, J. N., Stozkhov, Y., Tomé, A., Tröstl, J., Wagner, P. E., Wimmer, D., Winkler, P. M., Worsnop, D. R., and 
Carslaw, K. S. (2016). Global atmospheric particle formation from CERN CLOUD measurements. Science.

[Kirkby et al., 2016] Kirkby, J., Duplissy, J., Sengupta, K., Frege, C., Gordon, H., Williamson, C., Heinritzi, M., Simon, M., Yan, C., Almeida, J., Tröstl, J., Nieminen, T., Ortega, I. K., Wagner, R., Adamov, A., Amorim, A., Bernhammer, A.-K., Bianchi, F., Breitenlechner, M., Brilke, S., Chen, X., Craven, J., Dias, A., Ehrhart, S., Flagan, R. C., Franchin, A., Fuchs, C., Guida, R., Hakala, J., Hoyle, C. R., Jokinen, T., Junninen, H., Kangasluoma, J., Kim, J., Krapf, M., Kürten, A., Laaksonen, A., Lehtipalo, K., Makhmutov, V., Mathot, S., Molteni, U., Onnela, A., Peräkylä, O., Piel, F., Petäjä, T., Praplan, A. P., Pringle, K., Rap, A., Richards, N. A. D., Riipinen, I., Rissanen, M. P., Rondo, L., Sarnela, N., Schobesberger, S., Scott, C. E., Seinfeld, J. H., Sipilä, M., Steiner, G., Stozhkov, Y., Stratmann, F., Tomé, A., Virtanen, A., Vogel, A. L., Wagner, A. C., Wagner, P. E., Weingartner, E., Wimmer, D., Winkler, P. M., Ye, P., Zhang, X., Hansel, A., Dommen, J., Donahue, N. M., Worsnop, D. R., Baltensperger, U., Kulmala, M., Carslaw, K. S., and Curtius, J. (2016). Ion-induced nucleation of pure biogenic particles. Nature, 533(7604):521-526.

[Kulmala et al., 1998] Kulmala, M., Laaksonen, A., and Pirjola, L. (1998). Parameterizations for sulfuric acid/water nucleation rates. Journal of Geophysical Research: Atmospheres, 103(D7):8301-8307.

[Merikanto et al., 2007] Merikanto, J., Napari, I., Vehkamäki, H., Anttila, T., and Kulmala, M. (2007). New parameterization of sulfuric acid-ammonia-water ternary nucleation rates at tropospheric conditions. Journal of Geophysical Research: Atmospheres, 112(D15):n/a-n/a. D15207.

[Riccobono et al., 2014] Riccobono, F., Schobesberger, S., Scott, C. E., Dommen, J., Ortega, I. K., Rondo, L., Almeida, J., Amorim, A., Bianchi, F., Breitenlechner, M., David, A., Downard, A., Dunne, E. M., Duplissy, J., Ehrhart, S., Flagan, R. C., Franchin, A., Hansel, A., Junninen, H., Kajos, M., Keskinen, H., Kupc, A., Kürten, A., Kvashin, A. N., Laaksonen, A., Lehtipalo, K., Makhmutov, V., Mathot, S., Nieminen, T., Onnela, A., Petäjä, T., Praplan, A. P., Santos, F. D., Schallhart, S., Seinfeld, J. H., Sipilä, M., Spracklen, D. V., Stozhkov, Y., Stratmann, F., Tomé, A., Tsagkogeorgas, G., Vaattovaara, P., Viisanen, Y., Vrtala, A., Wagner, P. E., Weingartner, E., Wex, H., Wimmer, D., Carslaw, K. S., Curtius, J., Donahue, N. M., Kirkby, J., Kulmala, M., Worsnop, D. R., and Baltensperger, U. (2014). Oxidation products of biogenic emissions contribute to nucleation of atmospheric particles. Science, 344(6185):717-721.

[Usoskin et al., 2010] Usoskin, I. G., Kovaltsov, G. A., and Mironova, I. A. (2010). Cosmic ray induced ionization model crac:crii: An extension to the upper atmosphere. Journal of Geophysical Research: Atmospheres, 115(D10):n/a-n/a. D10302.

[Vehkamäki et al., 2002] Vehkamäki, H., Kulmala, M., Napari, I., Lehtinen, K. E. J., Timmreck, C., Noppel, M., and Laaksonen, A. (2002). An improved parameterization 
for sulfuric acid-water nucleation rates for tropospheric and stratospheric conditions. Journal of Geophysical Research: Atmospheres, 107(D22):AAC 3-1-AAC 3-10. 